\title{
A preliminary experimental investigation into the influence of compartment permeability on damaged ship response in waves
}

\author{
V.D.K.Domeh, A.J.Sobey* and D.A.Hudson
}

Fluid Structure Interactions, University of Southampton, University Rd, Southampton/England, SO17 1BJ

\begin{abstract}
:
After damage rapid and accurate guidance is necessary to safely recover vessels. An improvement in the understanding of ship behaviour after damage will increase chances of recovery of the vessel and safety for the ship crew and cargo, with corresponding benefits to the maritime environment. Whilst a number of studies have investigated static behaviour of damaged ships with permeability previous research at forward speed considers the damaged compartment to be empty. Novel aspects of this research include the study of a variety of permeabilities and internal arrangements of the damaged compartment for a ship moving in waves.
\end{abstract}

Results from experiments carried out in a towing tank using a segmented ship model show that permeability appears to have a large effect on the pitch and heave motion responses when the vessel is travelling at forward speed, with reduced effect for a stationary ship. Furthermore, results indicate that internal arrangement of compartments has less effect than compartment permeability on the damaged ship responses. Finally, the influence of damaged orifice size on the motion responses is investigated and the results show that at forward speed the responses are significantly affected and that they are largest for the minimum orifice size tested.

Keywords: Ship motions; Damaged Ship Response; Compartment Permeability; Experimental results; Forward Speed Motions

\section{Introduction}


The marine industry is always striving towards increased ship safety but due to the unpredictable nature of sea voyages, both from environmental factors and human intervention, ship damage continues to occur. Damage to ships can lead to loss of life and/or cargo but also leaves the vessel in a state where it can cause damage to the marine environment and from which salvage is expensive. In an effort to increase safety and to reduce the cost and environmental impact of damage, it is important to understand the likely behaviour of a damaged vessel in order to provide guidance to crew, owners and salvage teams.

A vital component of such guidance for damaged ship scenarios is to determine how compartment permeability affects the vessel so that crews and emergency response teams have a "rule of thumb" for emergency response scenarios. In this study, therefore, the effect of compartment permeability on vessel motion is investigated experimentally for a model-scale frigate with damage.

In Ruponen (2007), the flooding process that follows the creation of the damage opening can be divided into three main phases reiterated by the IMO (2003). Immediately after the occurrence of damage, there is a phase of transient flooding as the water rushes in through the damage opening. If the opening is large and is located on the side of the ship, this floodwater is likely to cause a large transient heeling moment. The possibility of the ship capsizing is high, due to the sudden loading, and therefore the time to capsize can be short, from only a few seconds to a few minutes. In the case of a small damage opening or for bottom damage, the transient phase is likely to be insignificant as the heeling angle will increase more slowly.

Following the transient phase there is a phase of progressive flooding as the water floods to undamaged compartments through internal openings between compartments, causing water levels in the flooded compartments to rise steadily. Moreover, the pressure of the floodwater may cause leaking through closed doors or even lead to collapse of internal structures. At this stage the crew are likely to be concentrating on securing the safety of the vessel and general guidance into how the vessel will behave in the damaged condition is likely to be of value. 
After this initial period, usually of 24 to $48 \mathrm{hrs}$, it is hoped that the vessel will have reached a quasi-static period until conditions change. It is at this stage where calculations will be used to determine the safety of the vessel and although information about the vessel and its damage may still be scarce, more informed decisions can be made. Finally, after a period of days or weeks the recovery of the vessel can start and calculations with larger computational times are now useful, together with more complete information on the vessel's status. It is during this period that salvage experts can determine the safest method by which to recover the vessel. The method that is cheapest and has least impact on the environment during recovery is allowing the vessel to recover under its own propulsion, this is followed, in order of cost and risk to the environment, by towing the vessel home, carrying on the back of another vessel and finally salvage at sea. It is of growing importance that the motions of these damaged vessels whilst underway are understood. Reports of a large oil spill off the Korean peninsula in December 2007 predict that damage to the environment could have been reduced if she had been given clearance to move, Yang et al. (2009). Suyuthi et al. (2013) investigated the fatigue of damaged ship hulls in the static condition but indicate the benefits of studies with forward speed. The more information available on how the vessel will behave in the damaged state the greater the likelihood of selecting the optimal method of recovery.

Damaged ship research has aimed to investigate the flooding process in its entirety by dividing the process into transient, progressive and steady state flooding phases. Vredeveldt, et al. (2000) discussed increasing the crashworthiness of a ship's side structure by reducing the permeability of the void spaces (compartments) in the side hull. This had the effect of reducing the roll of a damaged ship by restricting the sudden water ingress. Chan et al. (2001) showed that for a damaged Ro-Ro ship, the most critical condition is when she is in quartering seas. This work was extended in papers by Chan et al. (2002) and Korkut et al. (2003, 2004) where Korkut et al. (2004) provides an excellent survey of experiments performed up until that point. Palazzi and de Kat (2002) attempted to simulate the transient response of a damaged vessel in roll both through experiments and computational methods, investigating the feasibility of simulating the transient response at model scale. Lee et al. (2007) developed a model to show the dynamic behaviour of a damaged ship in waves testing a model in three scenarios: engine room bottom damage, side shell damage and bow visor damage of a Ro-Ro ship 
all with $100 \%$ permeability. Santos and Soares(2006) presented a theory coupling ship motions with water on deck in the time domain, concluding that often the damage has an adverse and non-linear effect on the structural loading and that the behaviour of the pressure values on the bulkheads are complex.

Santos et al. (2002) showed, with a Ro-Ro shaped barge, that an accumulation of water can occur near the damage opening when permeability is added to a compartment. This accumulation causes a transient heel, which becomes more important as the damage opening area increases. Eventually, if the damage size is sufficiently large and the barge has a Ro-Ro deck located relatively near the waterline, the deck edge may become immersed and flooding of that deck initiated. Ruponen et al. (2007) showed that accurate simulations can be developed to predict the floating position and water heights in the compartments providing that the discharge coefficients are known. Ruponen et al. (2010) went on to show that when real permeabilities were also included that the results were an even better match. It should be noted that for these results a small damage hole was used and therefore the results were more sensitive to discharge coefficient than for a larger value. Van't Veer et al. (2002) investigated a time to sink criteria based on a capsize criteria using 125 simulations of a large passenger ship incorporating permeability. The results show, for small sea states, that after the vessel have recovered from its first roll the mean angle does not change significantly and no capsize will occur. A rescue capsize of $12^{\circ}$ is investigated and this criteria is met in all sea states of $6.5 \mathrm{~m}$ and above and no $90^{\circ}$ capsize occur in any runs. This is supported by Lee et al. (2012) who performed experimental roll decay tests on intact and damaged vessels showed that the roll motions decreased rapidly during damage scenarios. Zhang et al. (2013) compared experiments with smooth particle hydrodynamics for sinking ships with empty compartments giving a good comparison but highlighting the nonlinearity and randomness of their experiments.

Santos and Guedes Soares (2008a) applied computational fluid dynamics with shallow water theory to their simulation. This method does not have the inaccuracies associated with hydraulic models when simulating flooding dynamics. Furthermore, Santos and Guedes Soares (2008b) showed that for some damage conditions that the shear force and bending moment can be higher during flooding than after this has finished. This led to Santos and Guedes Soares (2009) investigating the influence of the flood water on the roll motion during and after the transient phase. It was found that after the initial 
transient phase flow rates into compartments below the main deck remain significant. It was also shown that the vessel changes its dynamic performance when in waves and that the roll motion is damped when flooded. The effects of roll were further investigated by Schreuder et al. (2011) using different wave seeds and varying wave heights to study capsize boundaries. The results show that there is a limited wave height below which the probability of capsize is so low to be negligible to those in which there is a high probability after only a short time period.

Wood et al (2009) investigated parameters that affect the behaviour of a damaged ship using CFD simulations, showing that in the event of damage the size of damage created in the ship hull could have a significant impact on the behaviour of the damaged ship and its flooding rate. Smith (2009) experimentally investigated the behaviour of damaged ships using idealised damaged geometries and measuring the hydrodynamic forces on a damaged body, using this to develop a damage assessment tool based on strip theory. Leblanc (2011) investigated the effects of compartment permeability on added mass and damping of a damaged ship section. The results indicate that these flooding factors affect the added mass and damping of a damaged ship section and hence are likely to affect the resulting motions. Begovic et al. (2013) used both experimental and numerical techniques to obtain motions and loads for an intact and damaged frigate model in waves. Gao and Vassalos (2011) and Gao et al. (2012, 2013) have used a RANS based CFD solver to evaluate damaged ships, first demonstrating the suitability of the method and then investigating phenomena related to damage including sloshing, which is alleviated by damage, and roll decay of a Ro-Ro ferry and its behaviour in beam seas.

Despite these efforts, there are still relatively few data sets available for experiments on damaged ship structures to enable the verification of modelling tools and, in the short term, provide guidance for damaged vessels; this is especially limited for cases with forward speed. The aim of this research, therefore, is to study how variations of compartment permeability and internal arrangement (configuration), together with orifice size, affect the damaged vessel motion response to waves.

\section{Experimental Procedure}

\subsection{Experimental Setup}


Tests were conducted in a towing tank $60 \mathrm{~m}$ long, $3.7 \mathrm{~m}$ wide and $1.86 \mathrm{~m}$ deep with a maximum carriage speed of $4.5 \mathrm{~ms}^{-1}$. Unidirectional (long-crested) waves were generated using a single, motor-driven, paddle wavemaker. Wave reflections from the absorption beach have previously been measured using the technique of Isaacson (1991) as less than $10 \%$.

To facilitate measuring the elevation of waves produced, a resistance-type wave probe, with a length of $0.42 \mathrm{~m}$ was used throughout. Wave elevation was sampled at $100 \mathrm{~Hz}$ using a DaqView data acquisition system.

A 1/43.62 model scale Leander class frigate, the bodyplan and flexible model can be seen in Figure 1, was employed in carrying out the experiments. Principal particulars of the Leander class frigate at full and model scales are given in Table 1. The ship model is made up of four rigid segments. The segments are put together to form the complete model by being mounted on a flexible aluminium backbone beam, running through the entire length of the model. A rubber membrane is employed to seal the gaps between segments.

Heave response is measured using a linear potentiometer attached to the tow post and pitch response obtained from a rotary potentiometer in the tow fitting in the model, the model is constrained in all other four degrees of freedom. The model is ballasted to the required mass using weights distributed appropriately in each segment such that the stated pitch gyradius is achieved. Empty $330 \mathrm{ml}$ containers were used to simulate different compartment permeabilities during the experiments with different numbers of cans being placed to represent machinery, furniture and other obstructions within the compartments. Modifications were made to one segment of the ship hull to replicate damage. For this study, the second segment from the stern, which is $63.5 \mathrm{~cm}$ in length and $63.5 \mathrm{~cm}$ from the stern, was chosen as the damaged compartment.

\subsection{Coefficient of Discharge $\left(C_{d}\right)$ for Damage Orifice}

Two damage sizes were tested in this study. The first is a circular hole of diameter $10.2 \mathrm{~cm}$ and the second is a rectangular hole, orientated lengthways along the hull, of length $8.9 \mathrm{~cm}$ and breadth, $5.1 \mathrm{~cm}$. These holes were placed with their centre $84.7 \mathrm{~cm}$ from the stern of the vessel, $21.2 \mathrm{~cm}$ from the back of the compartment, and $1.6 \mathrm{~cm}$ from the centre line on the port side. The discharge coefficient was investigated as it can be 
used to describe all the pressure losses that are caused by an opening and is related to the flooding period. By employing a draining test as in Ruponen (2006), and an assumption that the waterplane area remained constant during the total duration of discharge, the discharge coefficients for each damage orifice were calculated as,

$C_{d}=S \frac{\sqrt{2 g H_{1}}-\sqrt{2 g H_{2}}}{T g A}$,

where $\mathrm{S}=1729.49 \mathrm{~cm}^{2}$ is the area of the free surface in the compartment designated for damage, $\mathrm{A}$ is the area of the perforation made in the hull (damage area), $\mathrm{g}$ is acceleration due to gravity, $H_{1}=19 \mathrm{~cm}$ is the initial water height from the level of perforation, $H_{2}=10 \mathrm{~cm}$ is the height after the test, and $\mathrm{T}$ is the draining time between the two water levels. The results of these tests are included for interest, which was repeated three times for each damage case, are shown in Table 2, together with the damage areas. There is a large variation in the results for the coefficient of discharge, as the time for discharge for the circular hole was so short however, the results show a reasonable approximation for holes of this size and shape as shown in Li et al. (2013).

\subsection{Experimental Procedure}

Procedures recommended by The International Towing Tank Conference (ITTC, 2011) were used where Table 3 assesses the conformity of experiments to the general guidelines for data acquisition and towing tank practice and Table 4 presents the recommended procedures specifically designed for seakeeping experiments. In all cases it is seen that the experiments were conducted according to current ITTC guidelines.

In total, eighty test runs were made with 20 mins between each test and each case was run twice. Where a result acquired did not conform to the trends found, the test was rerun. Tests were conducted at zero speed and $1.4 \mathrm{~m} / \mathrm{s}$ model scale representing the service speed of the vessel, 18 knots. The model was tested in regular waves for a range of encounter frequencies and a wave height to wave length ratio of $0.02(1 / 50)$ to represent the different sea states the frigate might encounter. The test wave frequencies are shown in Table 5 below. 
This experimental procedure results in six analogue voltage signals for each test run. One each for pitch and heave motions, two force signals, one each for drag and side force, and two wave probe signals, one each for wave amplitude and floodwater height in the damaged compartment. All signals were sampled using the DaqView acquisition software at a sampling rate of $100 \mathrm{~Hz}$, corresponding to a full scale value of $15.14 \mathrm{~Hz}$. The wave probes and heave and pitch potentiometers were calibrated assuming a linear relationship between output voltage and prescribed probe immersion, or applied displacement, respectively.

For each experimental run in the towing tank, recording commenced prior to the model being towed, in order to establish a zero-level on all channels. For damaged cases, this recording commenced once the model's position has reached equilibrium. The model was then run down the tank and encountered the waves. RAOs in heave and pitch were calculated for the segment of the run during which the vessel speed is constant and after initial transient oscillation upon encountering the waves had settled into a steadyoscillation (typically 2-3 encounters). The RAOs were calculated by subtracting the zero-level from the signals for heave and pitch and calculating the root mean square of the response (rms). The rms of the wave probe signal was taken for the same segment of the trace. The RAOs for heave and pitch are calculated as rms heave/rms wave and rms $\mathrm{pitch} / \mathrm{rms}$ wave slope, respectively.

\subsection{Model Configurations}

Permeabilities tested are based on the ITTC (2011) recommended, Procedure 7.5-02-0704.2, volume permeabilities for model tests on damage stability.

(1) Void spaces : $100 \%$

(2) Passenger or accommodation spaces : $80 \%$

(3) Engine room : 70\%

(4) Machinery room : 70\%

In the experiment, empty $330 \mathrm{ml}$ containers were stowed in the damaged compartment to achieve the various compartment permeabilities; Figures 2,3 and 4 shows the ship model ready for these tests where the dark patch, the rubber membrane, near to the tow post covers the damage. 
Tests commenced with an intact case where the opening in the damaged compartment was sealed as a baseline. This was followed by $100 \%, 80 \%$ and $70 \%$ permeability tests in which the seal was removed, the ship model was flooded and the towing began after flooding had occurred and the vessel had stabilised. Tests to investigate the effect of internal arrangement on damaged ship response were conducted at different configurations for the case of $80 \%$ permeability, for a circular damage opening and at zero speed. The tests using the rectangular hole were conducted at both zero and forward speeds, and $70 \%$ permeability.

For the $80 \%$ permeability case, three internal arrangement configurations were tested at zero forward speed. Configuration (1): all the containers were packed together at one end of the bulkhead in the compartment as shown in Figure 2, loosely representing one main engine. Configuration (2): the containers were separated into rows of two and one moved to the middle of the compartment. This represents, for example, two engines separated by a gap of $31.75 \mathrm{~cm}$ (half the length of the model segment designated for damage). Configuration (3): the set of containers in the middle were moved to the opposite bulkhead in the compartment to represent two engines separated by a gap of $63.50 \mathrm{~cm}$ (full length of model segment designated for damage) as shown in Figure 4 below.

\section{Results}

\subsection{Experimental Verification}

Denchfield (2011) investigated the influence of rogue waves on a travelling ship using a flexible Leander model in the intact condition for a variety of sea states including regular head seas at zero speed. Figure 5 and 6 shows the results of heave and pitch RAOs of Denchfield (2011) for regular head seas at zero speed compared to those measured in this study, showing, in general, good agreement between the measurements. The pitch response at a wave frequency around $0.6 \mathrm{rad} / \mathrm{sec}$ is higher in the current experiments.

\subsection{Variation in Compartment Permeability}


Having verified the experimental procedure it is possible to determine the manner in which ship compartment permeability affects the motions of the vessel. Figure 7 presents pitch RAO for a range of full scale encounter frequencies for both the intact ship and range of compartment permeabilities tested at zero (Figure 7a) and forward speed (Figure 7b), where configuration 1 is used for the $80 \%$ permeability. From Table 6 it is possible to see the variation between the two runs in the experiment, where the highlighted cells demonstrate a low repeatability, taken here as a difference of more than $10 \%$ between repeated experimental runs.

Overall, a generally low level of variability can be seen for the zero speed condition, especially in the intact case, where the difference between runs is within 5\% for all frequencies and $2 \%$ for most. For the damaged ship cases, the variability is under $10 \%$ for all frequencies with a $70 \%$ permeability. For $100 \%$ and $80 \%$ compartment permeability the variation is greater - particularly for the $80 \%$ case.

Examples of the time traces in heave and pitch for the damaged ship with zero speed and a $70 \%$ compartment permeability and for an encounter frequency of $0.66 \mathrm{rad} / \mathrm{sec}$ (ship scale) are given in Figures 8 and 9; these traces indicate a typical vessel response in waves. Similarly, Figures 10 and 11 present plots for the case of the ship travelling with forward speed and $70 \%$ compartment permeability, with the repeat data being shown in Figures 12 and 13.

For the cases with forward speed, the variation between runs is greater for all conditions. The low frequency results for no damage exhibit a variation under $\sim 6 \%$. After examining the time traces for each run, it is unclear why the variation between runs is greater in some cases than in others. It is proposed that the variation may be due to the dynamics of the floodwater in the compartment, but this is not apparent in the response traces in heave and pitch. In order to investigate this further would require measurement of the floodwater dynamics, itself a challenging problem and outside the scope of this initial investigation. There is a slight 'beat' effect seen in the wave trace which appears to correspond to a similar 'beat' in the traces for heave and pitch response. It is thus likely that this effect seen in the heave and pitch response is due to the encountered waves and not to any non-linear behaviour ascribed to the floodwater dynamics.

Looking at the values of the RAOs, for the zero speed cases (Figure 7a), the difference between permeabilities is small, with the exception of the value for $100 \%$ permeability 
at an encounter frequency of $0.660 \mathrm{rad} / \mathrm{sec}$. However, this frequency corresponds to the greatest variability between runs at this permeability.

For the forward speed cases (Figure 7b), there are much greater differences between the different values of permeability. The results for $70 \%$ permeability are distinctly different to those for all other cases; however this case is characterised by the greatest overall variability between runs. In general the compartment permeability affects the pitch response most in a region close to the pitch natural frequency.

Figure 14a presents the heave RAOs at zero speed where the values for different permeabilities are in close agreement. Variability between the two runs for each case tested at zero speed, shown in Table 7, is generally good, with all but the highest frequency tested being within $10 \%$. With forward speed the variability once again increases, as can be seen from Table 7. In this case the intact condition is again the most repeatable, with results for only one frequency exhibiting a difference of more than $10 \%$. For the $100 \%$ permeability case, all frequencies tested result in a relatively large difference between the runs. For $80 \%$ and $70 \%$ compartment permeabilities the results are similar. That is, all but the lowest test frequency exhibit more than $10 \%$ difference between repeated runs. These results are similar to those obtained in pitch, as would be expected.

From figure 14b, it may be observed that the heave RAO does not change much between the different compartment permeabilities, with the possible exception of the $70 \%$ permeability case, where there is a larger difference. However, as noted, this is also the compartment permeability that exhibits the most variability between runs. The differences between responses with repeat runs may be due to the vessel encountering slightly different wave properties from one run to the repeat run, causing differences in response. These differences may be magnified by the effects of forward speed and floodwater on the vessel response. When compared to the pitch responses, there is less change in response between the different compartment permeabilities.

\subsection{Variation in Internal Arrangement}


Having determined that the permeability of a compartment affects the responses of a ship in waves, it is important to investigate how the arrangement of the objects in the compartment affects the ship behaviour.

Figure 15 illustrates the pitch and heave responses for the vessel against zero speed, for the case having $80 \%$ compartment permeability and the three compartment configurations described in section 2.4. The results show a close agreement between all of the configurations tested, suggesting that in this case the internal arrangement of the damaged compartment does not affect the ship motions following damage.

\subsection{Variation in Damage Orifice Size}

It is also important to determine the manner in which the orifice size might affect the responses of the ship, following a damage event and flooding. To this end, the pitch RAOs for the damaged ship, with zero and forward speed are shown in figure 16 for $45.39 \mathrm{~cm}^{2}$ and $81.71 \mathrm{~cm}^{2}$ damage orifices. From these results, it appears that there is little difference in pitch RAO at zero speed for the different orifice sizes. However, when the vessel is travelling with forward speed, there is a large difference observed between the two cases investigated. This is replicated for the heave results shown in figure 17.

\section{Discussion}

The results obtained in this investigation and presented in section 3 have been compared to those of Korkut et al. (2004), where motion response tests were carried out on a small-scale model of a Ro-Ro vessel in regular waves for both intact and damaged conditions. The objective of the study was to explore the effect of the damage and wave heights on the model responses. The model was tested at zero speed in both intact and damaged conditions. Six degrees of freedom motion responses of the stationary model were measured over nine different wave frequencies and three different wave heights at each frequency for the head, beam and quartering sea conditions. Figure 18, taken from Korkut et. al. (2004), shows that the heave motion response of the intact model in head seas does not display any significant differences between the intact and damaged conditions. Figure 19, comparing the pitch motions for the intact and damaged ship model similarly indicates only small differences between the two conditions. 
Whilst the test conditions for Korkut et al. (2004) are not the same as those of this study, as they use empty compartments and do not account for permeability; it is useful to compare the results. In comparing Figures 7 and 14 to figures 18 and 19, it can be seen that for both sets of results at zero speed there is little difference between the intact and damaged ship motions. However, the present study highlights the potential for these differences to be greater when the ship is travelling with forward speed. The change in behaviour may, at least to some extent, be caused by the permeability of the compartment it should be noted that the experimental results of Korkut et al. pertain to a Ro-Ro ferry whereas the present work is for a naval frigate creating differences in response. Whilst many damaged ships may stay stationary post-damage to reduce economic and environmental impact, or if the damage is too severe to allow movement, in many circumstances it may be beneficial to tow a vessel or indeed let it return to port under its own power such as in the case highlighted by Yang et al. (2009). The present study therefore indicates that it is important to investigate further the effects of damage on ship motions at forward speed. Given the close relationship between ship motions and structural loading, this is also important for assessing the strength of the ship in the damaged condition. As part of any future work, section 3.4 indicates that the size of the orifice must also be included. The present study indicates that the internal arrangement within a flooded compartment is of less importance but that relevant permeabilities for the compartment should be taken into account, as supported by Leblanc (2011).

\section{Conclusions}

Experiments have been performed into the effects of compartment permeability, internal arrangement and damage orifice size on the response of a vessel in waves, using a segmented model. The effects of these different parameters on pitch and heave responses were investigated at zero and forward speed. As a result of these experiments, the following conclusions can be drawn:

i. Compartment permeability does not appear to have a significant effect on the pitch and heave responses at zero speed, in agreement with the previous research Santos et al. (2002) and Korkut (2004);

ii. Compartment permeability has a greater effect on pitch and heave responses when the vessel is travelling at forward speed; 
iii. Whilst tests on the intact vessel show good repeatability, the variation between nominally identical tests is larger than would be expected for the damaged vessel. It remains unclear as to why this is the case and therefore this requires further investigation and more detailed experimentation. Internal arrangement appears to have only a minimal effect on pitch and heave responses for frigate type vessels travelling at forward speed;

iv. Damage orifice size has a more significant effect on pitch and heave responses at forward speed.

Whilst this study does not provide a comprehensive data set, it does highlight interesting behaviour and provide evidence that further investigations should be made into damaged vessel responses, especially at forward speed. This is particularly important given the potential for reducing the impact of damage if vessels can move. If this is the case modelling the loads to assess the consequences for the strength of ships following a damage event will become even more important. Guidance is given on the direction future investigations should take in an area of current interest as highlighted by recent publications (e.g. Begovic et al. (2013), Gao and Vassalos (2012) and Gao et al. (2011, 2013)). Therefore, it is hoped that this study will provide a further step in reducing the environmental and economic impact of vessel recovery by providing guidance to crews and emergency response specialists.

\section{References}

Begovic, E., Day, A.H., and Incecik, A. (2013), Experimental assessment of intact and damaged ship motions in head, beam and quartering seas, Ocean Engineering, vol. 72 , pp. 209-226

Chan, H.S., Incecik, A. and Atlar, M. (2001). Structural Integrity of a Damaged RoRo Vessel. Proceedings of the second international conference on collision and grounding of ships, Technical University of Denmark, Lybgby, pp. 253-258.

Chan H.S., Incecik A. and Atlar M. (2002) Large amplitude motion responses of a Ro-Ro ship to regular oblique waves in intact and damaged conditions, Journal of Marine Science and Technology, vol. 7, pp. 91-99.

Denchfield, S.S. (2011), An Investigation of the Influence of Rogue Waves on a Travelling Ship, PhD Thesis, University of Southampton, UK.

Gao, Z., Gao, Q.and Vassalos, D. (2011), Numerical simulation of flooding of a damaged ship, Ocean Engineering, vol. 38, pp.1649-1662. 
Gao, Z., Gao, Q.and Vassalos, D. (2013), Numerical study of damaged ship flooding in beam seas, Ocean Engineering, vol. 61, pp. 77-87.

Gao, Q. and Vassalos, D. (2012), Numerical study of damage ship hydrodynamics, Ocean Engineering, vol. 55, pp.199-205.

IMO (2003), Large Passenger Ship Safety: Time - to - Flood Simulations for a Large Passenger Ship - Initial Study, IMO SLF46/INF.3 MARIN Report No. 17870 - 1 - CPS, 40pp.

Isaacson, M. (1991), Measurement of regular wave reflection, Journal of Waterway, Port and Coastal Engineering, vol. 117, pp. 533-569.

ITTC, 2011, Proceedings of the 26th International Towing Tank Conference, $26^{\text {th }}$ International Towing Tank Conference, Rio De Janeiro, Brazil.

Korkut, E., Atlar, M. and Incecik, A. (2003), An Experimental Study of Motion Behaviour with an Intact and Damaged Ro-Ro Ship Model, DEXTREMEL Report.

Korkut H.S., Atlar M. and Incecik A. (2004), An experimental study of motion behaviour with an intact and damaged Ro-Ro ship model, Ocean Engineering, 31: 483-512.

Leblanc, P.L. (2011), Hydrodynamic loading of a damaged ship section, MSc Thesis, University College London, UK.

Lee, D., Hong, S.Y. and Lee, G.-J. (2007), Theoretical and experimental study on dynamic behaviour of a damaged ship waves, Ocean Engineering, vol. 34, pp.21-31.

Lee, S., You, J.-M., Lee, H.-H., Lim, T., Rhee, S.H., and Rhee, K.-P., (2012) Preliminary tests of a damaged ship for CFD validation, International Journal of Naval Architecture and Ocean Engineering, Vol. 4, Issue 2, pp. 172-181.

Li, Y. A. J. Sobey and M. Tan. (2013) Investigation into the Effects of Petalling on Coefficient of Discharge during Compartment Flooding, Journal of Fluids and Structures, Vol. 45, pp.66-78.

Palazzi L., de Kat J. (2002), Model experiments and simulations of a damaged ship with air-flow taken into account, Proceedings of the 6th International Ship Stability Workshop, Webb Institute, USA.

Ruponen, P.(2006), Experimental Study on Progressive Flooding, Proceedings of Maritime Institute of Finland Seminar, Finland.

Ruponen, P. (2007), Progressive flooding of a damaged passenger ship, PhD Thesis, Helsinki University of Technology, Finland.

Ruponen, P., Sundell,T., Larmela, M., (2007), Validation of a simulation method for progressive flooding, International Shipbuilding Progress, 54(4), 305-321.

Ruponen, P., Kurvinen,P., Saisto,I., Harras,J., (2010), Experimental and numerical study on progressive flooding in full-scale, Transactions of Royal Institution of Naval Architects, International Journal Maritime Engineering, A-197-A-207 
Santos, T.A., and Guedes Soares, C. (2006), Study of the dynamics of a damaged passenger Ro-Ro ship, Proceedings of the $9^{\text {th }}$ international conference on the stability of ships and ocean vehicles, Rio de Janeiro, Brasil, vol. 2, pp. 587-598.

Santos, T. A. and Guedes Soares, C., (2008a), Study of damaged ship motions taking into account floodwater dynamics, Journal of Marine Science and Technology, 12:291-307.

Santos, T. A. and Guedes Soares, C., (2008b), Global Loads due to Progressive Flooding in Passenger Ro-Ro Ships and Tankers, Ships and Offshore Structures, 3(4), 289-302.

Santos, T. A. and Guedes Soares, C. (2009) Numerical Assessment of Factors Affecting the Survivability of Damaged Ro-Ro Ships in Waves, Ocean Engineering, 36, pp. 797-809.

Santos, T. A., Winkle, I. E., and Guedes Soares, C., (2002), Time Domain Modelling of the Transient Asymmetric Flooding of Ro-Ro Ships, Ocean Engineering, 29(6), pp. 667-688.

Schreuder, M., Hogström, P., Ringsberg, J.W., Johnson, E., Janson, C.-E., (2011), A method for assessment of the survival time of a ship damaged by collision, Journal of Ship Research, 55(2), pp. 86-99.

Smith, T.W.P. (2009). Wave loading on damaged ship, PhD Thesis, University College London, UK.

Suyuthi, A., Leira, B.J. and Riska, K. (2013), Fatigue damage of ship hulls due to local ice-induced stresses, Applied Ocean Research, vol. 42, pp.87-104

Van 't Veer, R., de Kat, J.O. and Cojeen, P., 2002, "Large Passenger Ship Safety:

Time to Sink", Marine Technology, 41 (2), pp. 82-88

Vredeveldt, A.W., Journee, J.M.J and Vermeer, H. (2000), The Effect of Crashworthiness and Solid Buoyancy on Survivability of Damaged and Flooded RoRo Ships, Proceedings of the Seventh International Conference on Stability of Ships and Ocean Structure,. Launcheston, Tasmania

Wood, C.D., Hudson, D.A. and Tan, M. (2009), CFD Simulation of Orifice Flow for the Flooding of Damaged Ships, Proceedings of the $12^{\text {th }}$ Numerical Towing Tank Symposium, Duisburg, Germany.

Yang, J., Rhee, S.H. and Kim, H. (2009), Propulsive performance of a tanker hull form in damaged conditions, Ocean Engineering, vol. 36, pp.133-144.

Zhang, A, Cao, X., Ming, F and Zhang, Z. (2013), Investigation on a damaged ship model sinking into water based on three dimensional SPH method, Applied Ocean Research, vol. 42, pp. 24-31 
Table 1: Principal particulars of Leander class frigate

\begin{tabular}{|l|c|c|}
\hline Dimension & Full Scale & Model Scale \\
\hline Length overall, $\mathrm{L}_{\mathrm{OA}}(\mathrm{m})$ & 113.4 & 2.6 \\
Length between perpendiculars, $\mathrm{L}_{\mathrm{BP}}(\mathrm{m})$ & 109.72 & 2.52 \\
Midships beam, $\mathrm{B}_{\text {mid }}(\mathrm{m})$ & 12.36 & 0.29 \\
Midships draught, $\mathrm{T}_{\operatorname{mid}}(\mathrm{m})$ & 4.19 & 0.096 \\
Maximum draught, $\mathrm{T}_{\max }(\mathrm{m})$ & 4.36 & 0.1 \\
Displacement, $\Delta($ tonnes $)$ & 2921 & 29.4 \\
LCG aft midships $(\mathrm{m})$ & 3.69 & 0.091 \\
Service speed, $\mathrm{V}_{\mathrm{s}}(\mathrm{knots}, \mathrm{m} / \mathrm{s})$ & 18 & 1.4 \\
Maximum speed, $\mathrm{V}_{\max }(\mathrm{knots})$ & 30 & \\
Pitch gyradius, $\mathrm{k}_{55}(\% \mathrm{LOA})$ & 25.26 & 25.26 \\
\hline
\end{tabular}

Table 2: Test results for the averaged $C_{d}$ of damage orifices.

\begin{tabular}{|c|c|c|c|c|c|}
\hline $\begin{array}{c}\text { Damage } \\
\text { Orifice }\end{array}$ & $\begin{array}{c}\text { Test } \\
\text { Run }\end{array}$ & $\begin{array}{c}\mathrm{A} \\
\left(\mathrm{cm}^{2}\right)\end{array}$ & $\begin{array}{c}\mathrm{T} \\
(\mathrm{s})\end{array}$ & $\mathrm{C}_{\mathrm{d}}$ & $\begin{array}{c}\text { Average } \\
\mathrm{C}_{\mathrm{d}}\end{array}$ \\
\hline & $(1)$ & & 2.25 & 0.508 & \\
Circular Hole & $(2)$ & 81.71 & 1.80 & 0.635 & 0.648 \\
& $(3)$ & & 1.43 & 0.800 & \\
\hline $\begin{array}{c}\text { Rectangular } \\
\text { Hole }\end{array}$ & $(1)$ & & 4.10 & 0.502 & \\
& $(2)$ & 45.39 & 3.98 & 0.517 & 0.539 \\
\hline
\end{tabular}

(a)

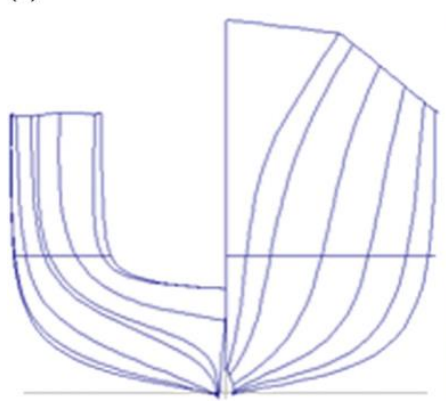

(b)

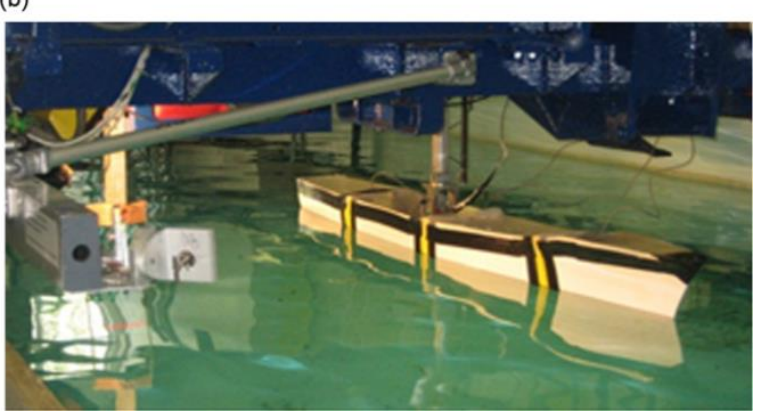


Figure 1: a) Vessel bodyplan and b) flexible model Bennet et al. (2013)

Table 3: Application of ITTC Recommended Procedures for Towing Tank Practice to experiments.

\begin{tabular}{|c|c|c|c|c|}
\hline ITTC Procedure & Section & Parameter & ITTC Recommended & Applied \\
\hline $7.5-02-07-02.1$ & 2.13 & $\begin{array}{c}\text { Minimum sample } \\
\text { rate }\end{array}$ & $4.0 \mathrm{~Hz}$ full scale & $15.14 \mathrm{~Hz}$ full scale \\
\hline $7.5-02-07-02.1$ & 2.13 & $\begin{array}{c}\text { Interval between } \\
\text { tests }\end{array}$ & 20 minutes & $\begin{array}{c}20 \\
\text { minutes }\end{array}$ \\
\hline $7.5-02-07-02.1$ & 2.1 & $\begin{array}{c}\text { Side-wall } \\
\text { blockage effects }\end{array}$ & $\begin{array}{c}5.10 \mathrm{rad} / \mathrm{s}(\mathrm{Fn}=0.121) \\
3.06 \mathrm{rad} / \mathrm{s}(\mathrm{Fn}=0.201) \\
2.19 \mathrm{rad} / \mathrm{s}(\mathrm{Fn}=0.282)\end{array}$ & $\begin{array}{c}3.016 \mathrm{rad} / \mathrm{s} \text { to } \\
5.969 \mathrm{rad} / \mathrm{s}\end{array}$ \\
\hline
\end{tabular}

Table 4: Application of ITTC Recommended Procedures for Seakeeping Tests to experimental results.

\begin{tabular}{|l|c|c|l|l|c|}
\hline Procedure & Section & Parameter & $\begin{array}{l}\text { Wave } \\
\text { Type }\end{array}$ & $\begin{array}{l}\text { ITTC } \\
\text { Recommended }\end{array}$ & Applied \\
\hline $7.5-02-07-02.1$ & 2.11 & $\begin{array}{c}\text { Regular wavelength } \\
\text { range }\end{array}$ & Regular & $\begin{array}{r}\text { Minimum } 0.5 \mathrm{~L}_{\mathrm{BP}} \\
\text { Maximum } 2.0 \mathrm{~L}_{\mathrm{BP}}\end{array}$ & $\begin{array}{r}0.502 \mathrm{~L}_{\mathrm{BP}} \\
1.79 \mathrm{~L}_{\mathrm{BP}}\end{array}$ \\
\hline $7.5-02-07-02.1$ & 2.11 & Suitable $\mathrm{H} / \lambda$ & Regular & 0.02 & 0.02 \\
\hline & & & & &
\end{tabular}




\begin{tabular}{|c|c|c|c|c|c|}
\hline $7.5-02-07-03.2$ & 2.3 & & & $5($ Minimum) & \\
$7.5-02-07-02.1$ & 2.11 & Number of cycles & Regular & 10 (Standard) & $12.00 \pm 5.00$ \\
$7.5-02-07-03.2$ & 2.3 & & & 20 (Maximum) & \\
\hline
\end{tabular}

Table 5: Encounter frequencies tested at model and full scales.

\begin{tabular}{|c|c|}
\hline $\begin{array}{c}\text { Model Frequency } \\
(\mathrm{rad} / \mathrm{s})\end{array}$ & $\begin{array}{c}\text { Ship Frequency } \\
(\mathrm{rad} / \mathrm{s})\end{array}$ \\
\hline 3.173 & 0.480 \\
3.305 & 0.500 \\
3.701 & 0.560 \\
4.361 & 0.660 \\
5.215 & 0.790 \\
6.276 & 0.950 \\
\hline
\end{tabular}

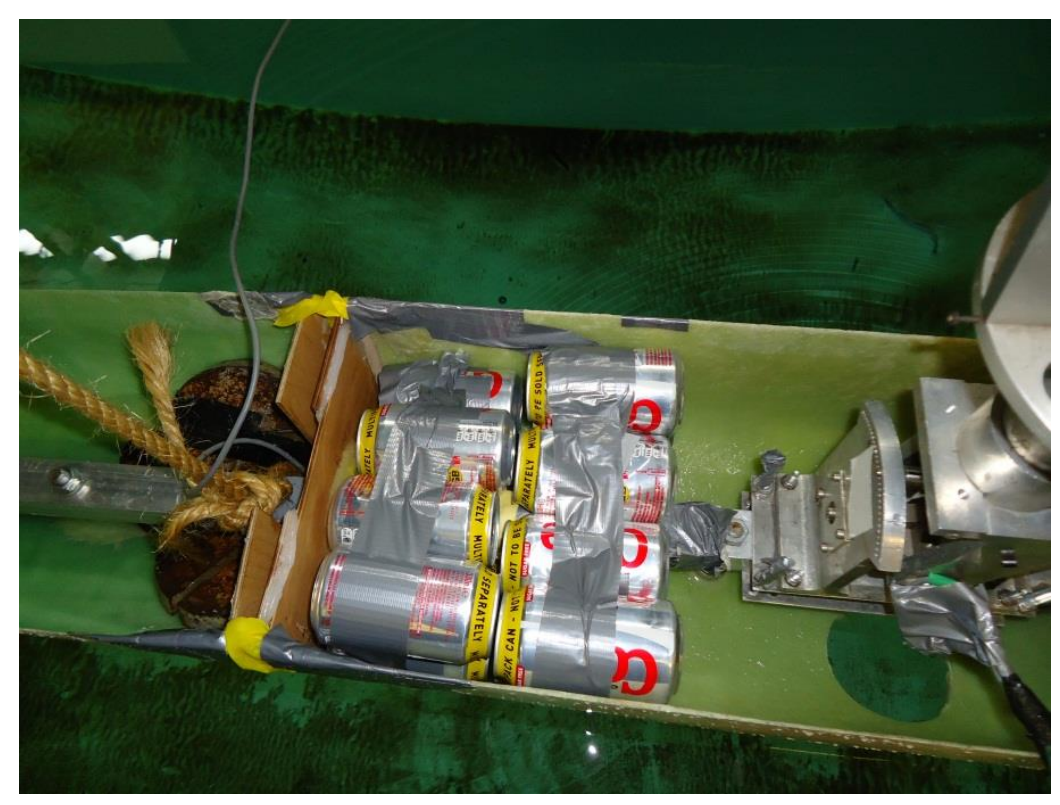


Figure 2: Ship model prepared for $80 \%$ permeability test runs representing Configuration (1).

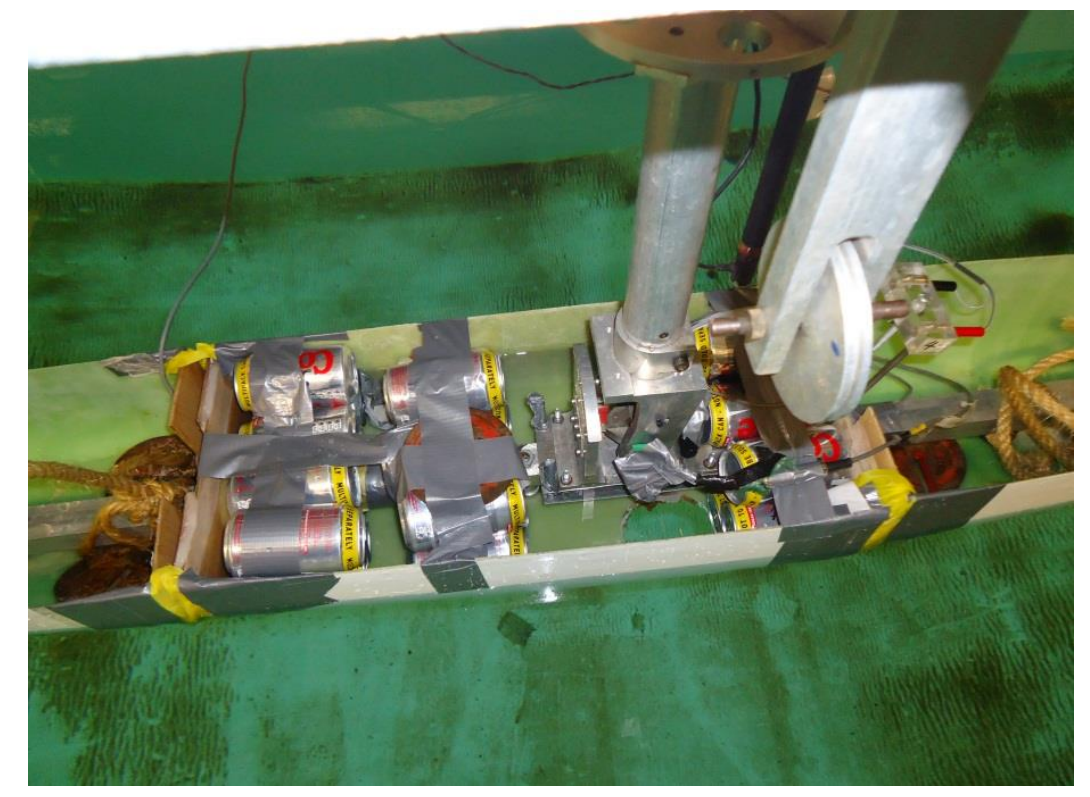

Figure 3: Ship model prepared for $70 \%$ permeability test runs.

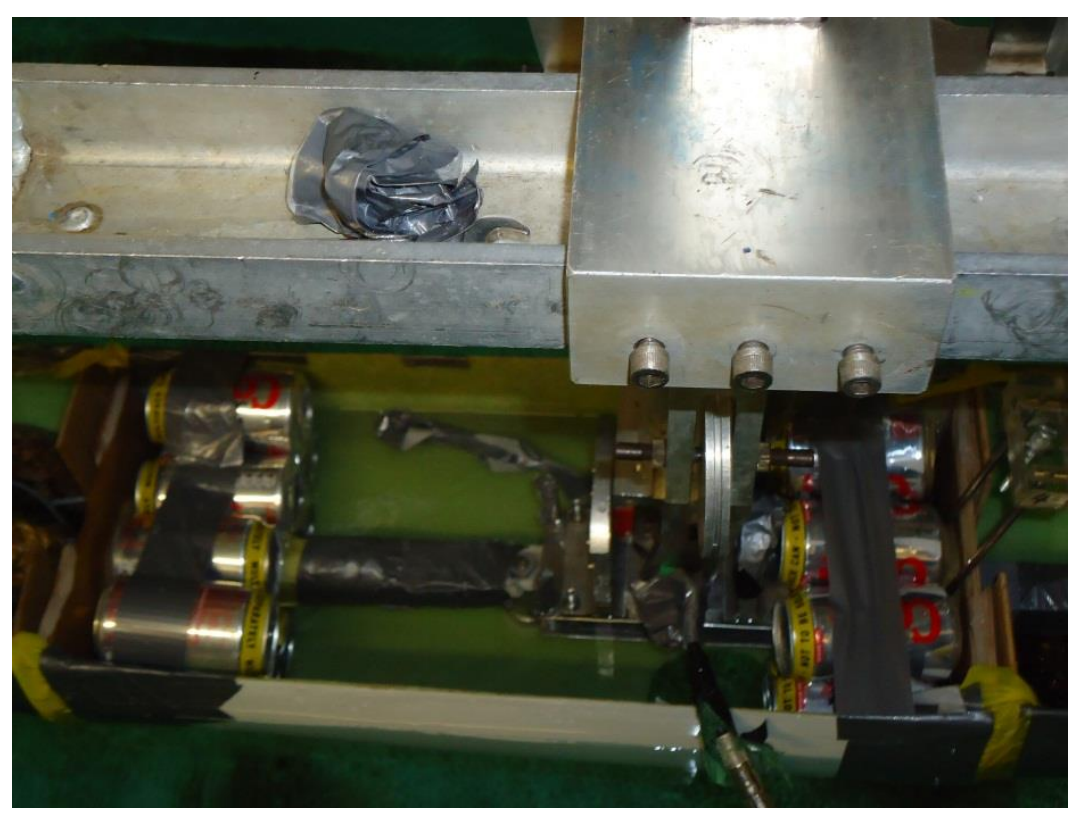

Figure 4: Ship model ready for Configuration (3) test runs. 


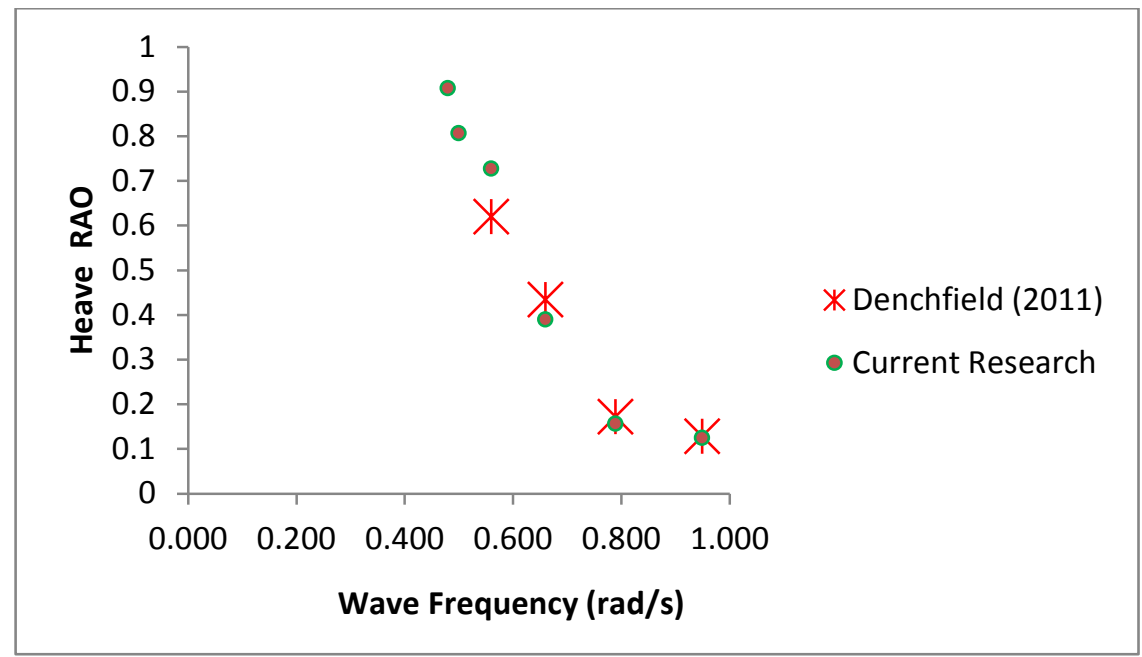

Figure 5: Intact condition heave for Denchfield (2011) and current research.

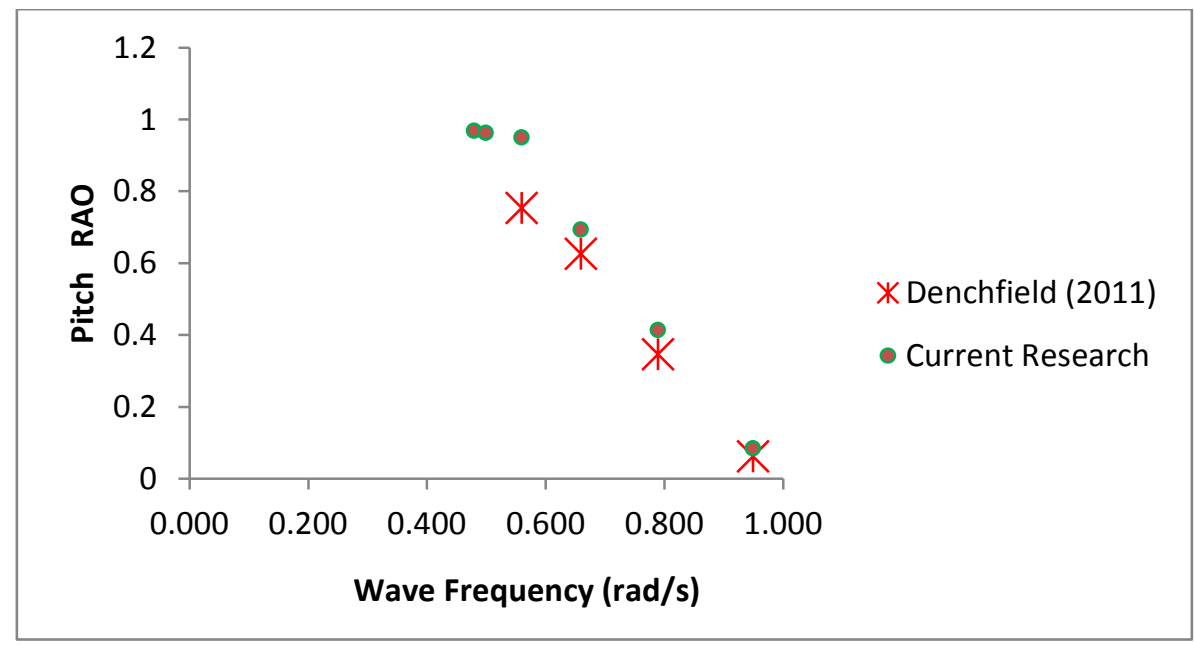

Figure 6: Intact condition pitch for Denchfield (2011) and current research. 

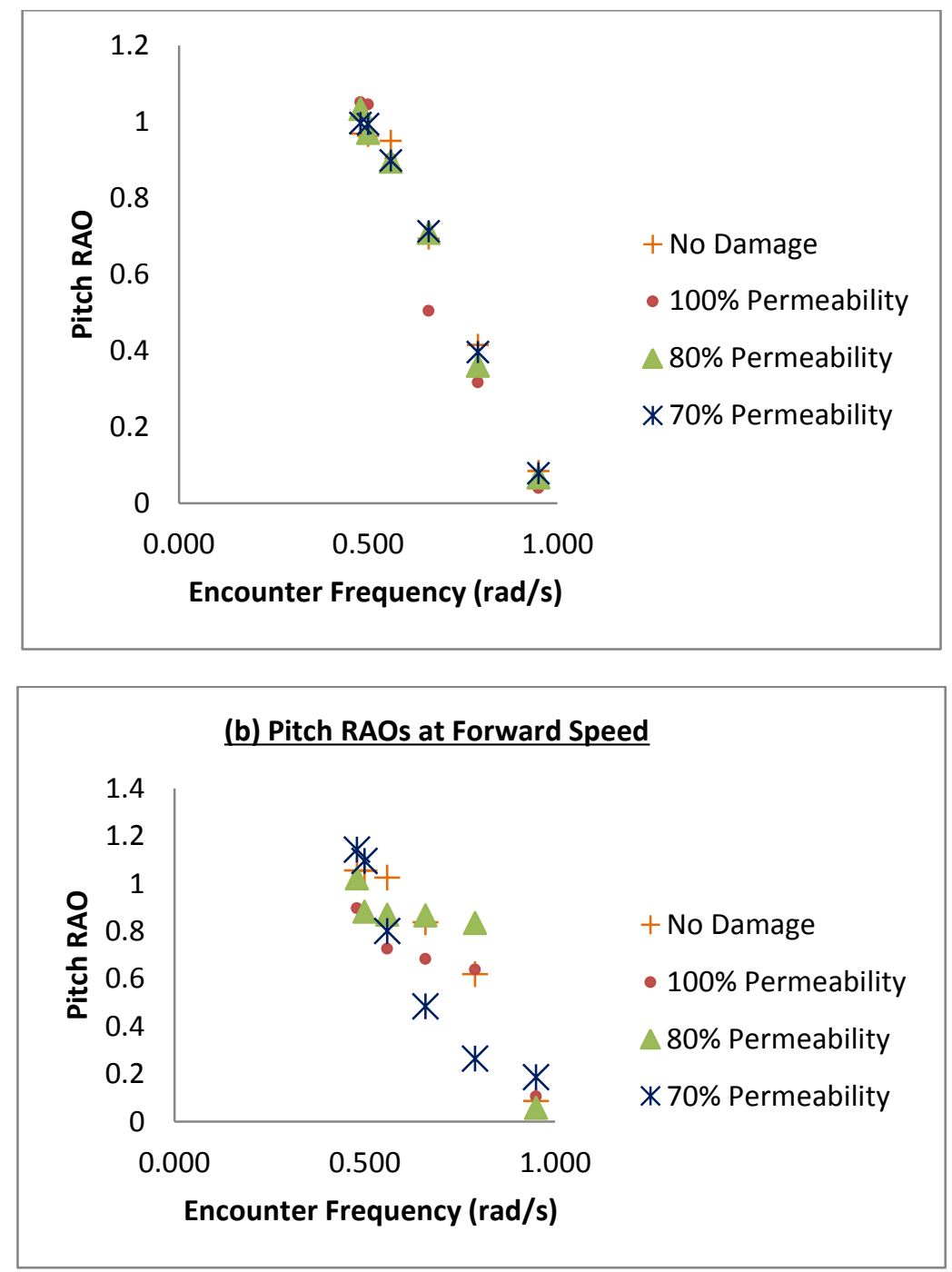

Figure 7: Pitch RAO for varying compartment permeability's at a) zero speed and b) forward speed. 


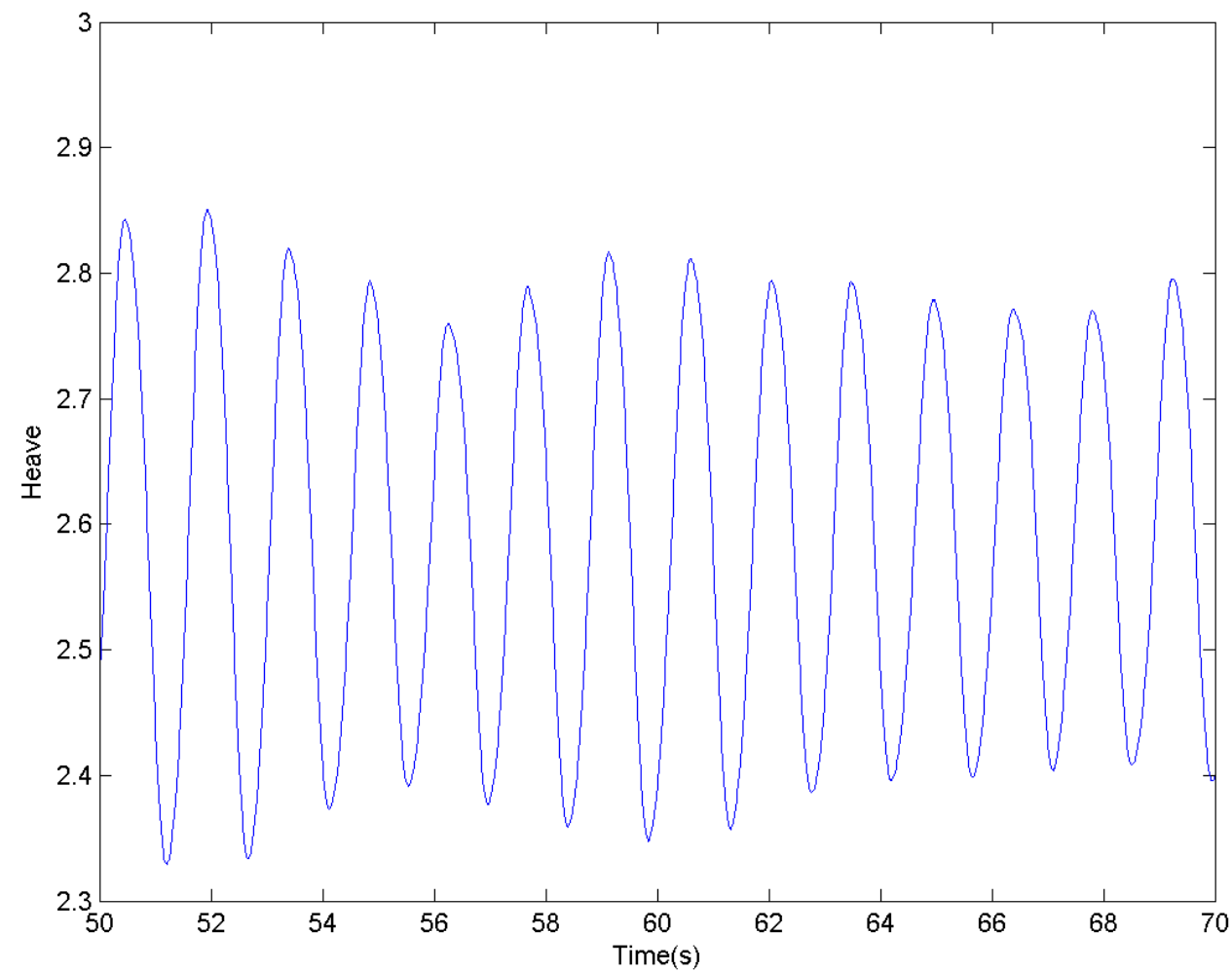

Figure 8: Heave time traces for $70 \%$ compartment permeability at zero speed 


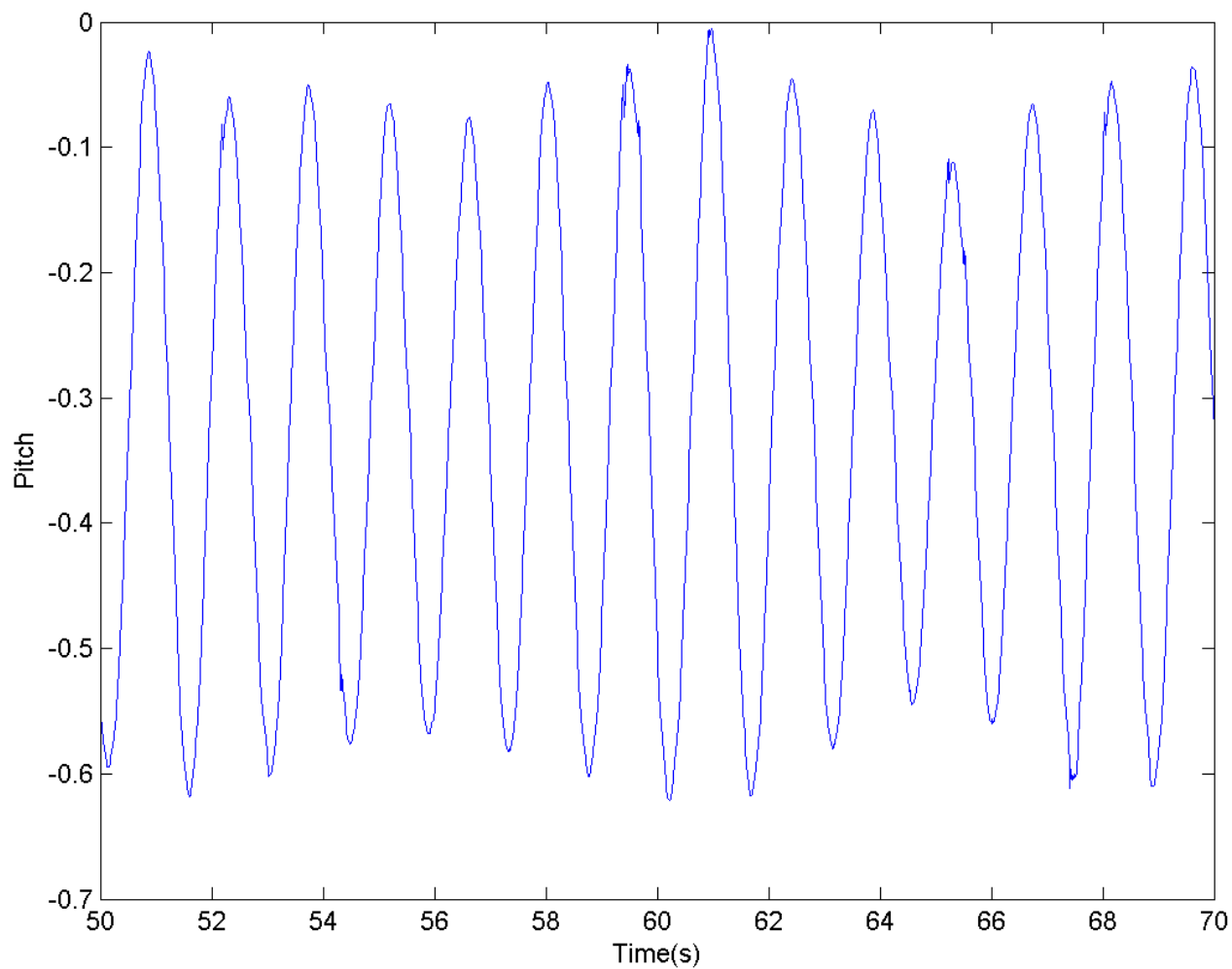

Figure 9: Pitch time traces for $70 \%$ compartment permeability at zero speed

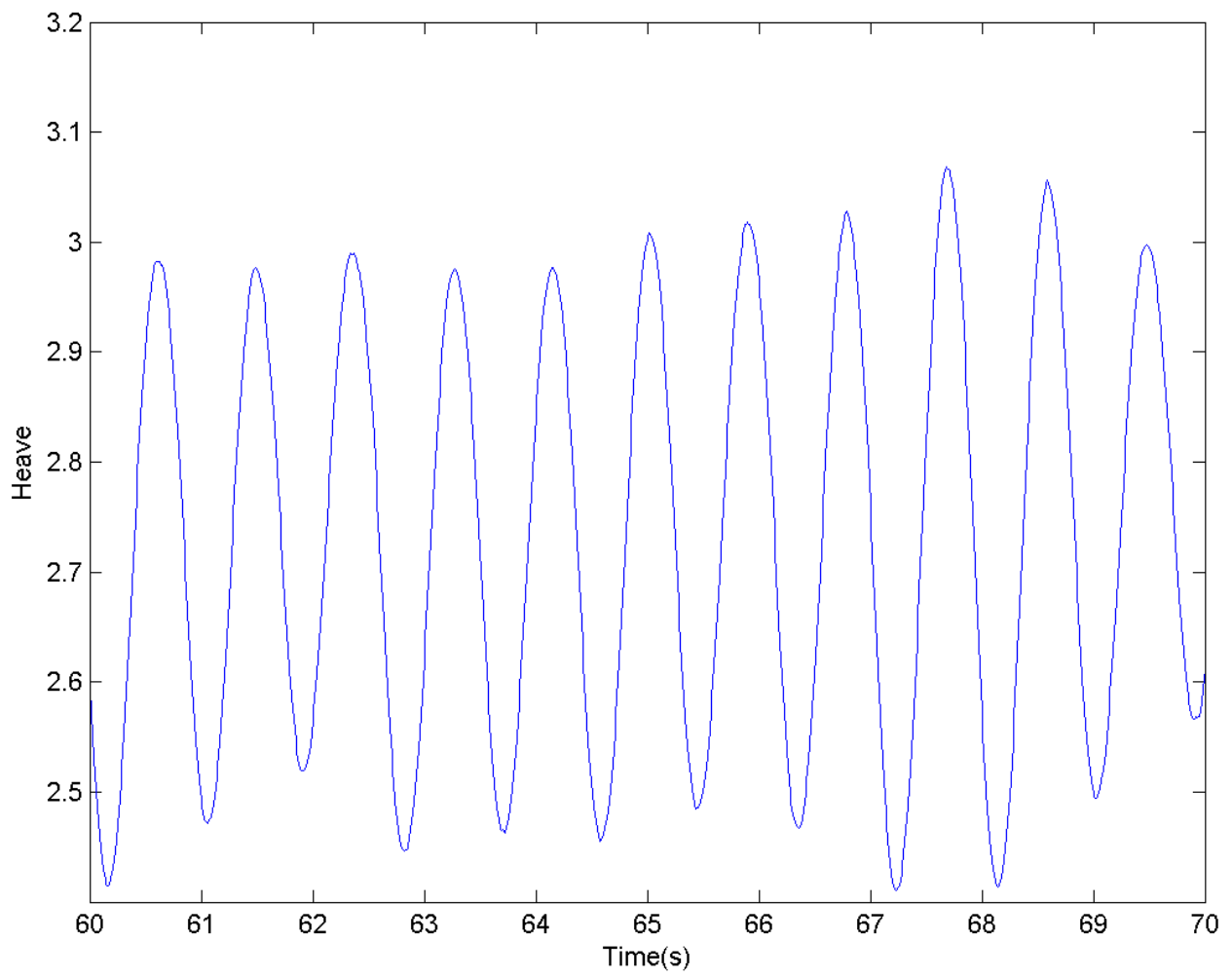

Figure 10: Heave time traces for $70 \%$ compartment permeability at forward speed 


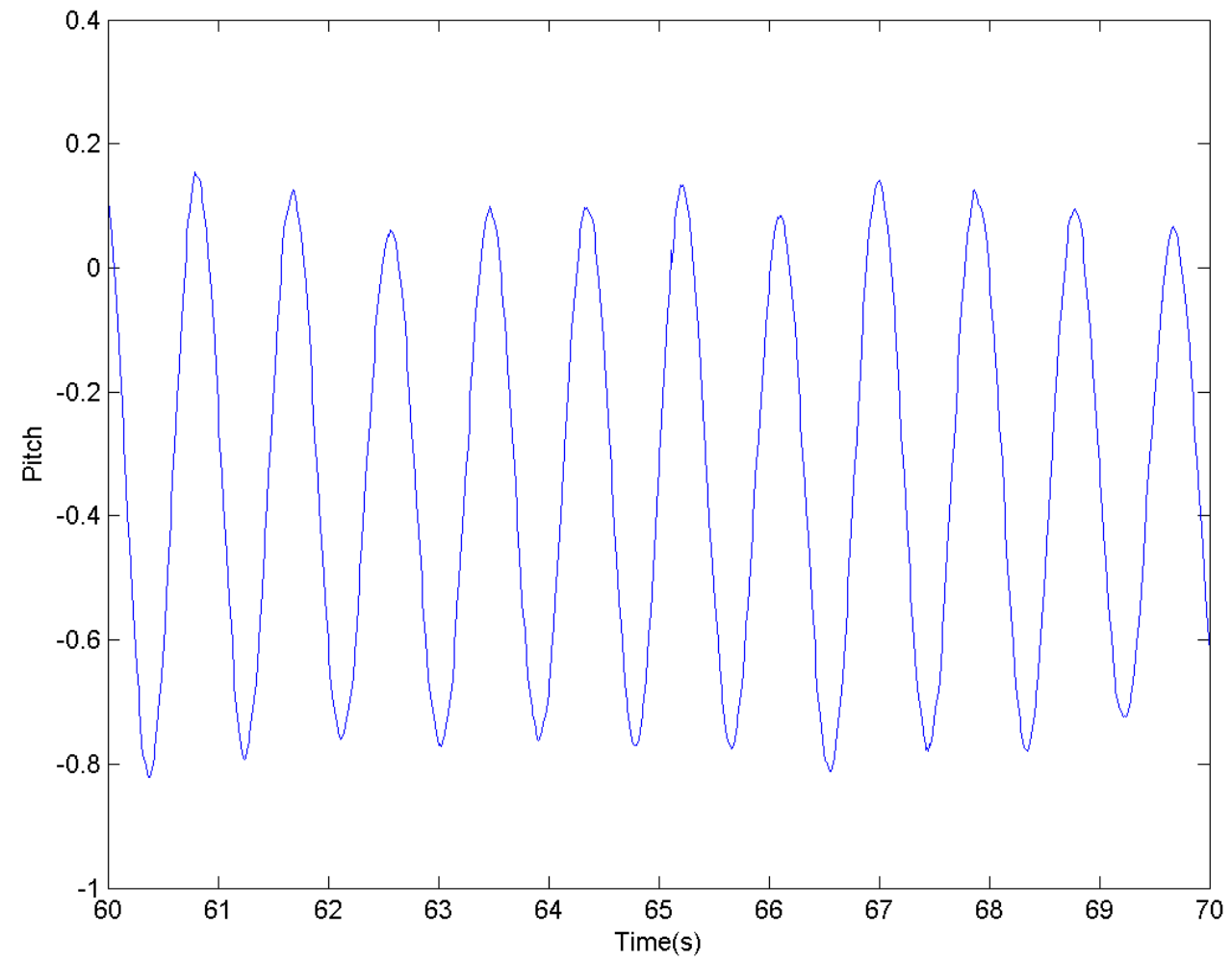

Figure 11: Pitch time traces for $70 \%$ compartment permeability at forward speed

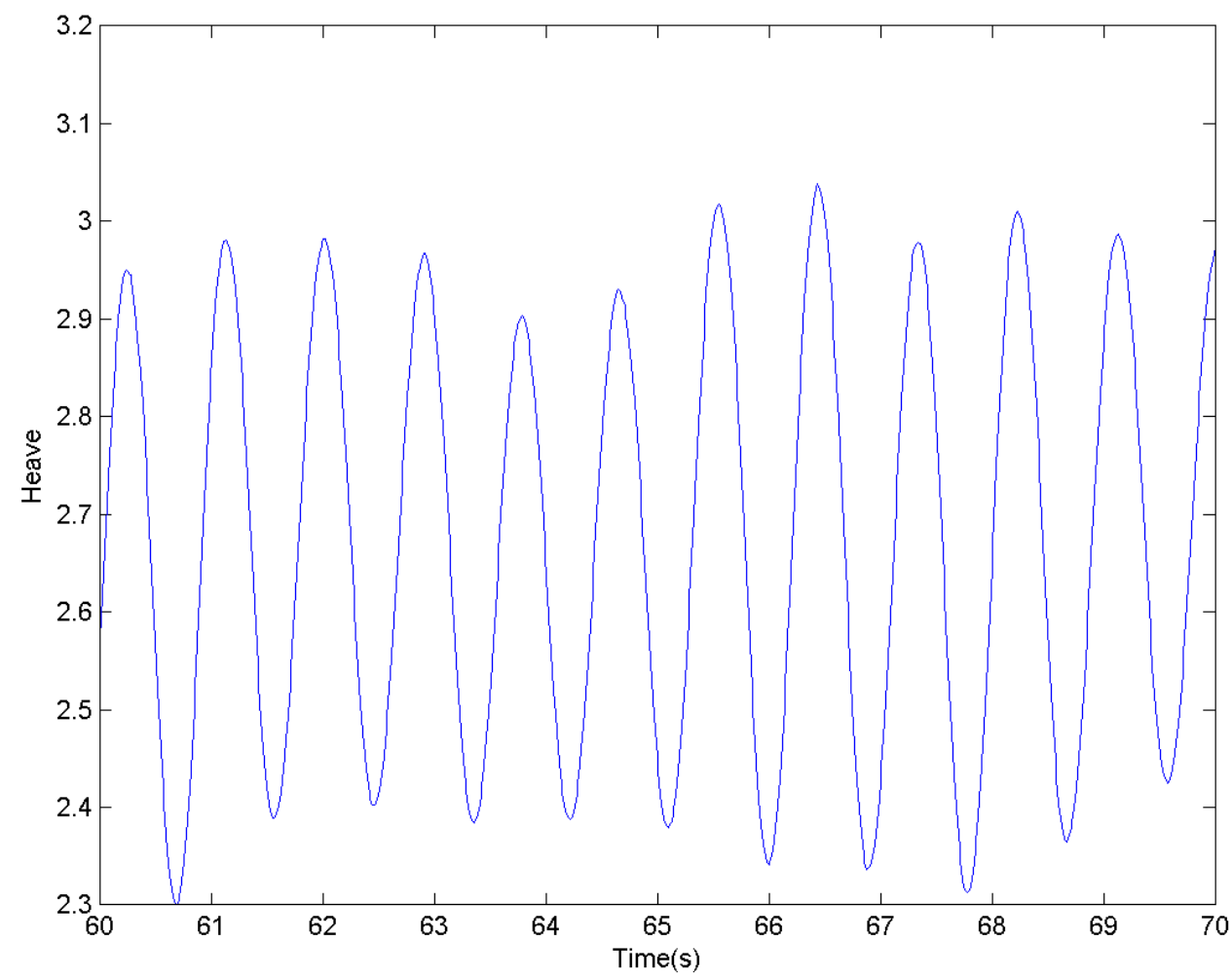

Figure 12: Repeat heave time traces for $70 \%$ compartment permeability at 


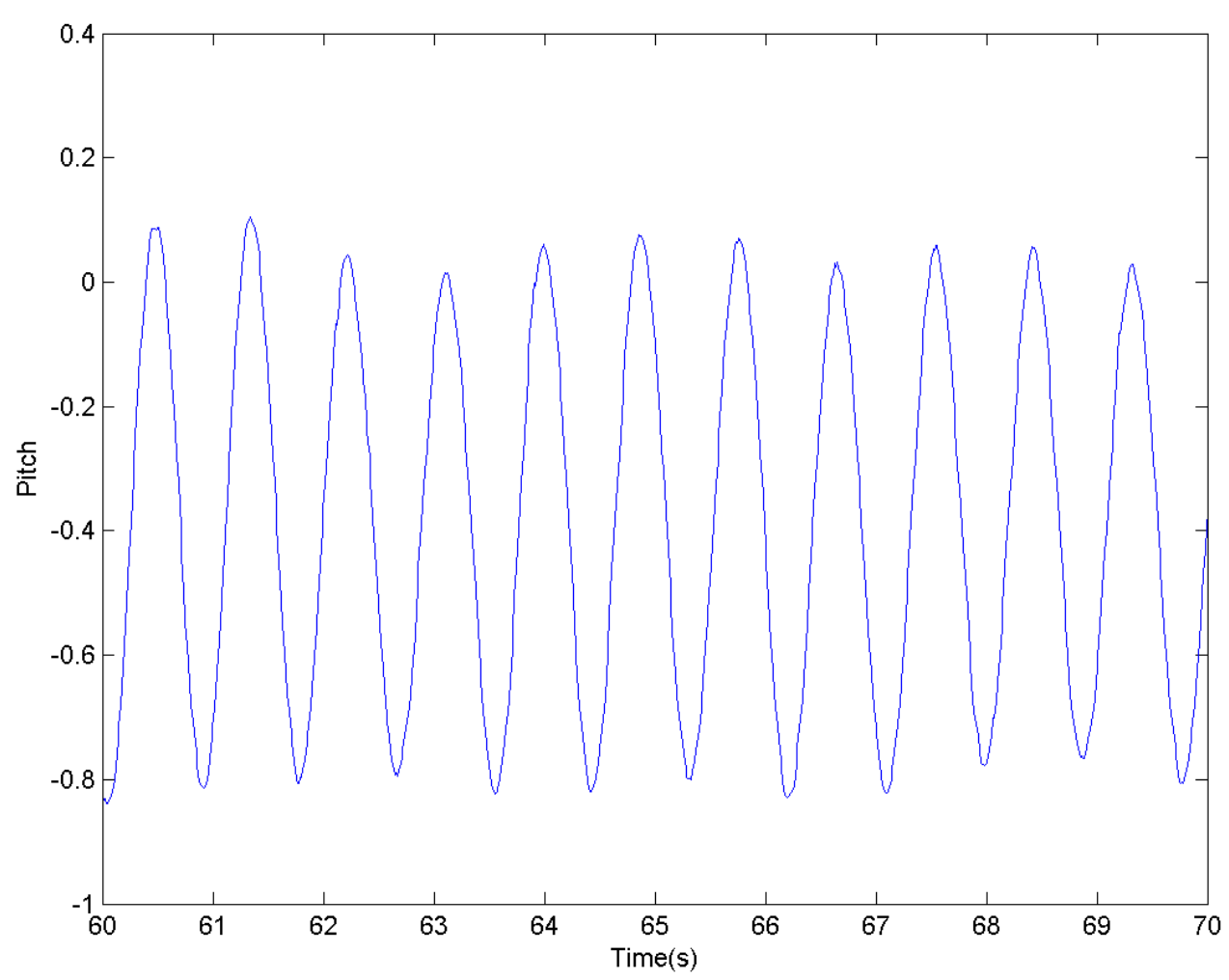

Figure 13: Repeat pitch time traces for $70 \%$ compartment permeability at forward speed

Table 6: Percentage change in pitch between repeated experiments (first and second runs)

\begin{tabular}{|c|c|c|c|c|c|c|c|c|}
\hline \multicolumn{5}{|c|}{ Zero Speed } & \multicolumn{3}{c|}{ Forward Speed } \\
\hline $\begin{array}{c}\omega_{\mathrm{e}} \\
(\mathrm{rad} / \mathrm{s})\end{array}$ & $\begin{array}{c}\text { No } \\
\text { Damage }\end{array}$ & $100 \%$ & $\begin{array}{c}80 \% \\
\text { Config. } \\
1\end{array}$ & $70 \%$ & $\begin{array}{c}\text { No } \\
\text { Damage }\end{array}$ & $\begin{array}{c}100 \% \\
80 \%\end{array}$ & $\begin{array}{c}70 \% \\
\text { Config. } \\
1\end{array}$ & \\
\hline 0.48 & 1.86 & 4.57 & 8.82 & 0.80 & 5.02 & 10.93 & 0.39 & 13.47 \\
\hline 0.50 & 1.04 & 6.32 & 5.05 & 0.30 & 5.31 & 10.45 & 13.70 & 30.14 \\
\hline 0.56 & 4.43 & 1.00 & 3.36 & 6.07 & 6.04 & 23.95 & 12.30 & 28.21 \\
\hline 0.66 & 0.86 & 27.69 & 12.29 & 0.98 & 3.58 & 23.75 & 7.28 & 35.74 \\
\hline
\end{tabular}




\begin{tabular}{|l|l|l|l|l|l|l|l|l|}
\hline 0.79 & 1.45 & 6.33 & 11.67 & 1.00 & 10.65 & 15.92 & 3.47 & 45.28 \\
\hline 0.95 & 0.00 & 2.50 & 34.33 & 1.27 & 24.56 & 14.63 & 18.97 & 44.92 \\
\hline
\end{tabular}
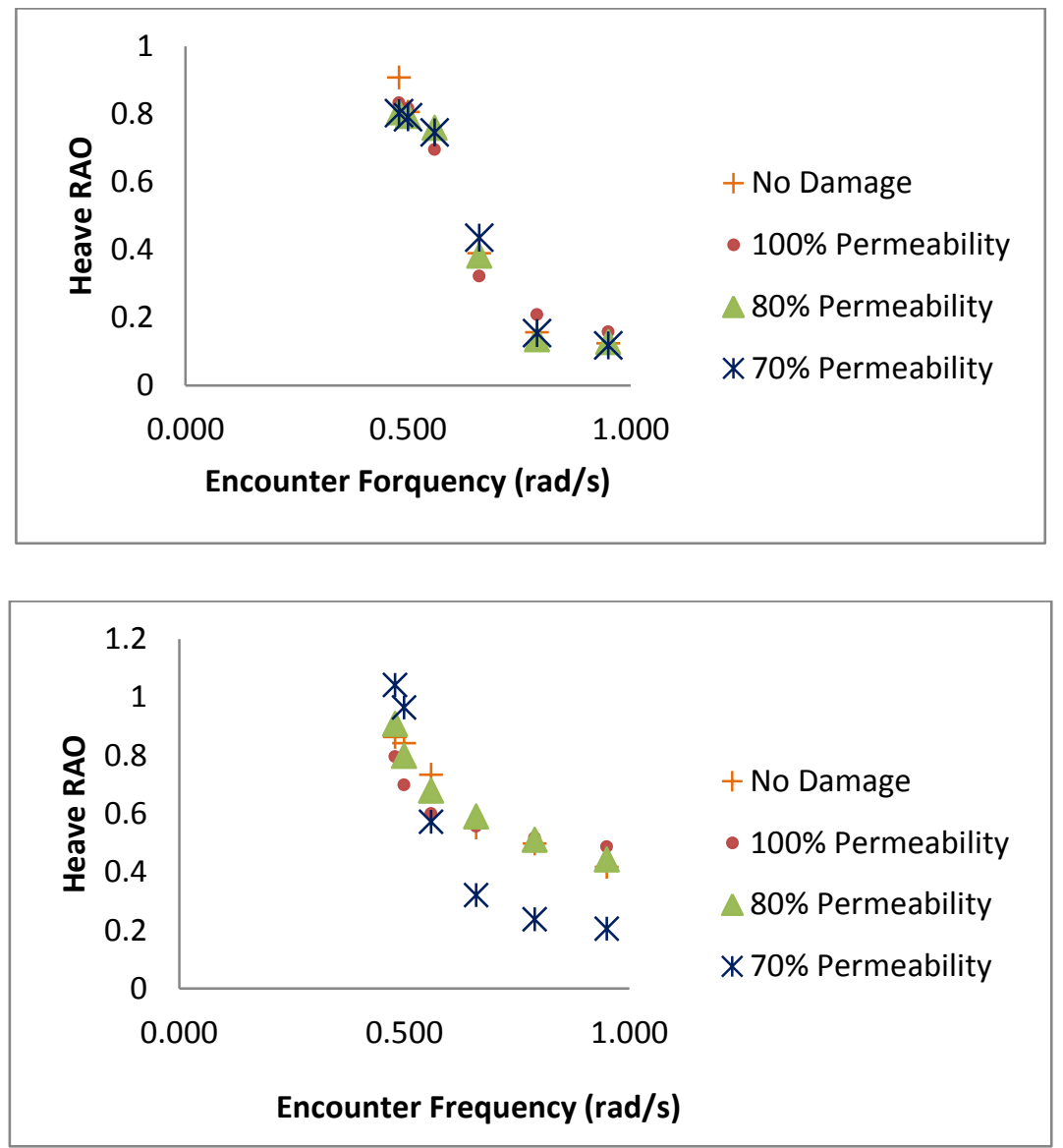
Figure 14: Heave RAO for varying compartment permeability's at a) zero speed and b) forward speed.

Table 7: Percentage change in heave between repeated experiments (first and second runs)

\begin{tabular}{|c|c|c|c|c|c|c|c|c|}
\hline \multicolumn{5}{|c|}{ Zero Speed } & \multicolumn{3}{c|}{ Forward Speed } \\
\hline $\begin{array}{c}\omega_{\mathrm{e}} \\
\mathrm{rad} / \mathrm{s})\end{array}$ & $\begin{array}{c}\text { No } \\
\text { Damage }\end{array}$ & $100 \%$ & $80 \%$ & $70 \%$ & No & $100 \%$ & $80 \%$ & $70 \%$ \\
\hline 0.48 & 9.93 & 3.59 & 0.86 & 11.09 & 6.60 & 19.94 & 2.37 & 6.44 \\
\hline 0.50 & 1.95 & 0.98 & 0.87 & 7.71 & 3.56 & 25.19 & 11.04 & 25.41 \\
\hline 0.56 & 5.50 & 3.21 & 5.01 & 4.12 & 1.08 & 27.31 & 21.25 & 13.99 \\
\hline 0.66 & 3.08 & 34.62 & 0.00 & 9.66 & 4.71 & 23.42 & 17.62 & 49.84 \\
\hline 0.79 & 4.49 & 4.59 & 34.15 & 3.14 & 11.27 & 19.25 & 16.01 & 51.69 \\
\hline 0.95 & 10.48 & 7.10 & 21.12 & 10.00 & 5.04 & 13.39 & 26.09 & 69.12 \\
\hline
\end{tabular}

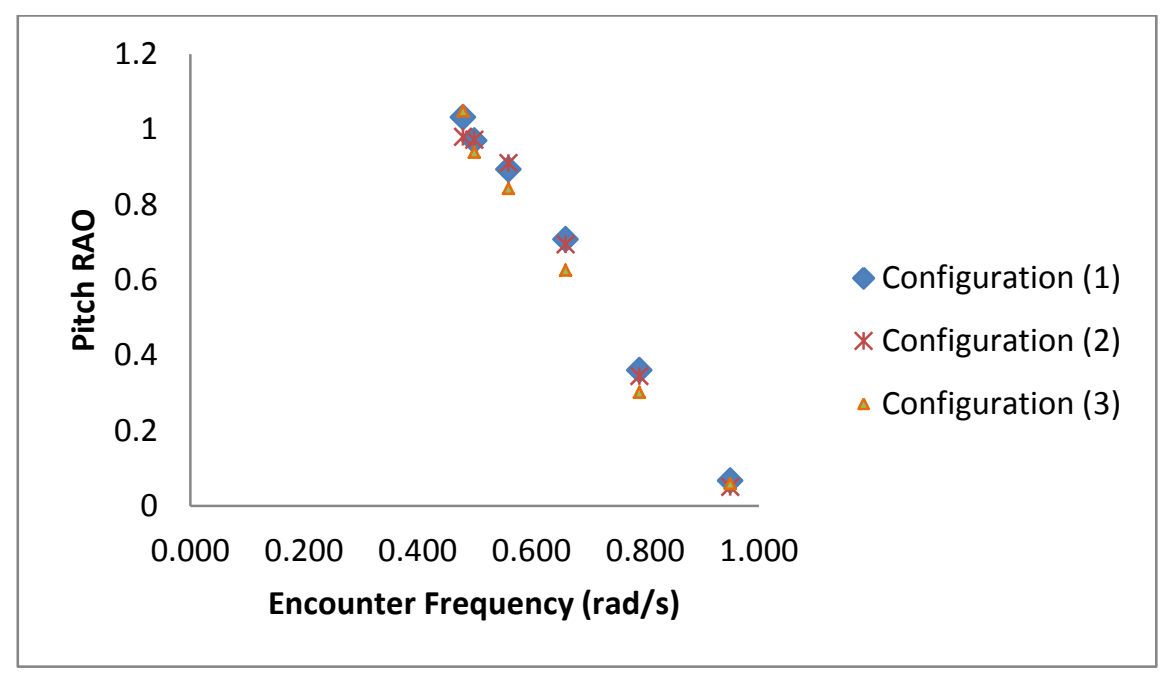




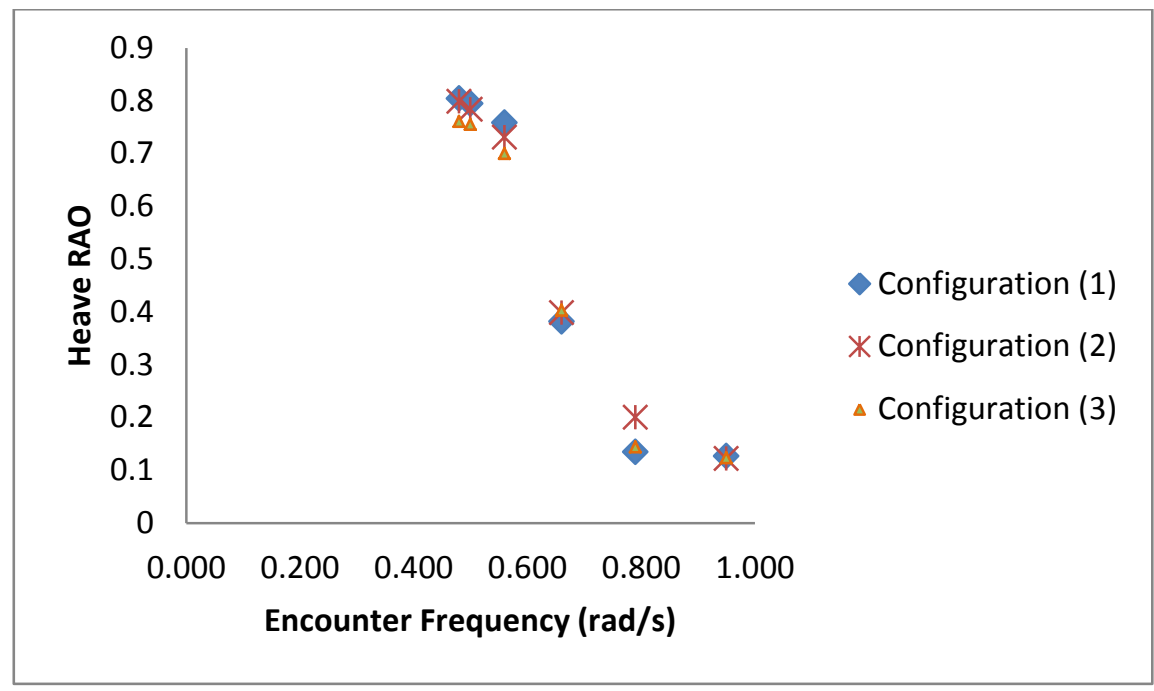

Figure 15: a) heave and b) pitch responses for $80 \%$ compartment permeability and three internal arrangements.
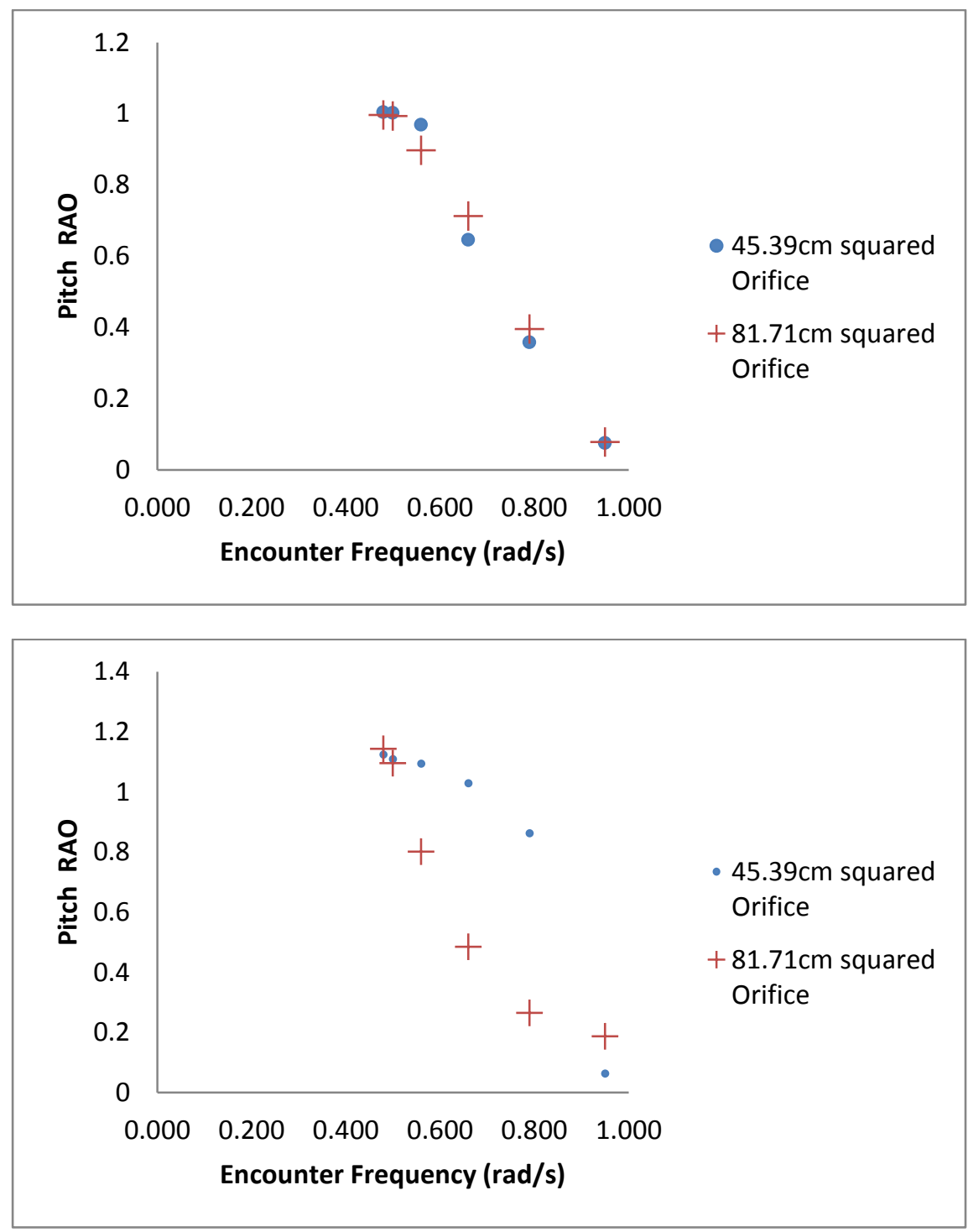
Figure 16: Pitch RAOs for two orifice sizes at a) zero speed b) forward speed.
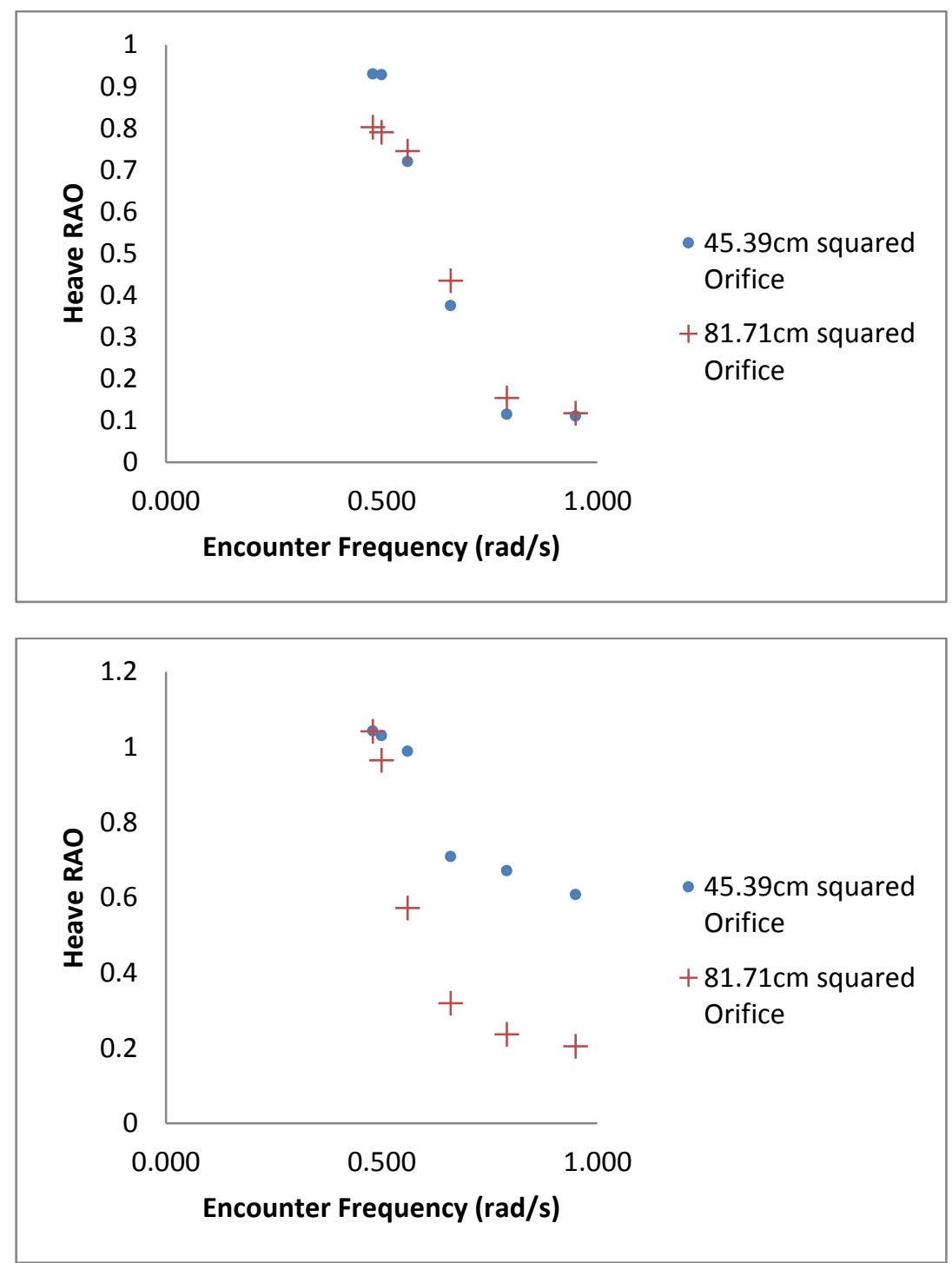

Figure 17: Heave RAOs for two orifice sizes at a) zero speed b) full speed. 


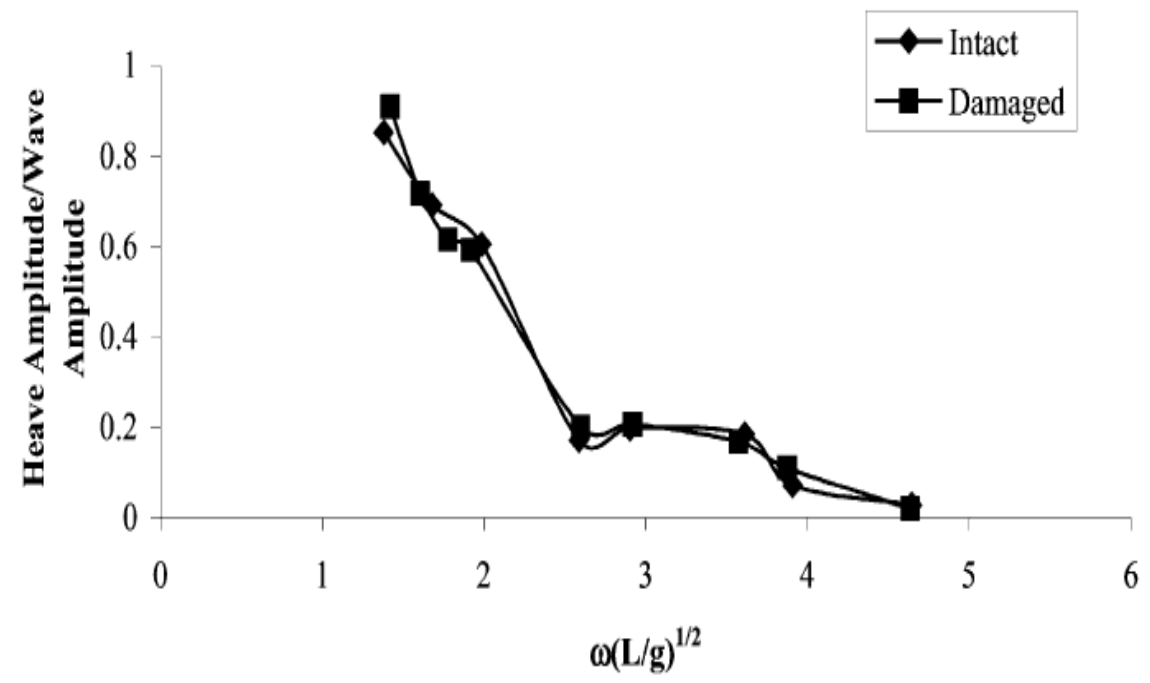

Figure 18: Heave RAOs in head seas for a model Ro-Ro vessel in intact and damaged conditions (taken from Korkut et al. (2004)).

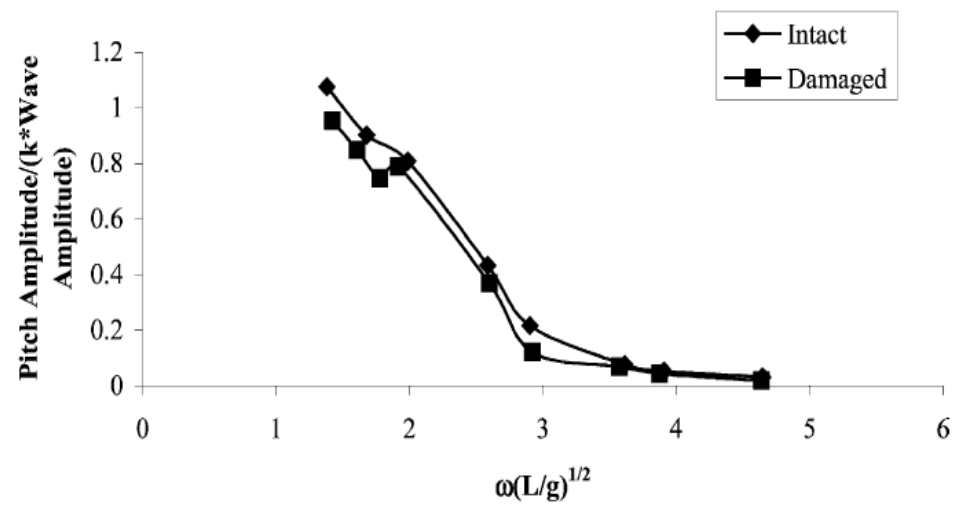

Figure 19: Pitch RAOs in head seas for a model Ro-Ro vessel in intact and damaged conditions (taken from Korkut et al. (2004)). 